\title{
THE IMPACT OF R\&D EXPENDITURE ON THE DEVELOPMENT OF GLOBAL COMPETITIVENESS WITHIN THE CEE EU COUNTRIES
}

\author{
- Dana Kiselakova, Beata Sofrankova, Veronika Cabinova, Erika Onufero- \\ va, Janka Soltesova
}

\begin{abstract}
This paper examines the relations between the R\&D expenditure and the global competitiveness development in the case of Slovakia as well as in member states of the European Union from Central and Eastern Europe (CEE EU (11)). To assess the competitiveness of CEE EU (11) member states, we used the Global Competitiveness Index (GCI) processed by the World Economic Forum (WEF). By using the correlation analysis, we focused on the detection of interrelations between the R\&D expenditure height (per capita) (using five variables of GERD) and values of the overall GCI score as well as its three main subindexes in the case of CEE EU (11) countries over the period of 2007 - 2016. In doing so, we determined that an increase in R\&D expenditures can significantly contribute to an increase in the CEE EU (11) countries' competitiveness level. All performed analyses confirmed that it is important to focus on increasing R\&D expenditures, especially in the higher education sector, as it has a significant influence on improving the global competitiveness development of the CEE EU (11) countries in the case of the 1st and 3rd GCI subindexes. In the end, it will be also reflected in the overall competitiveness assessment of this group of countries.
\end{abstract}

Keywords: CEE EU (11) countries, Global Competitiveness Index, RひD expenditure per capita, correlation analysis

JEL Classification: O30, O32, O57, F63

Received: May, 2018

1st Revision: July, 2018

Accepted: July, 2018

\section{INTRODUCTION}

Measuring and increasing global competitiveness is a complex and difficult process. In recent decades, economic science, as well as practices, have been paying increasing attention to innovation, considered to be the main driver for countries' economic competitiveness and growth. As reported by Hunady et al. (2017), innovation potential still differs significantly not only among EU regions, and R\&D expenditure seems to be the key factor determining the innovation potential and performance of a region. According to Szarowska (2017), R\&D is fundamental for 
the knowledge-based economies' competitiveness, and support of R\&D and innovation is also a political measure. In line with the Lisbon strategy and Europe 2020 targets, investment in European R\&D should be increased to 3\% of GDP, but this target has not yet been reached. From this point of view, Habanik et al. (2016) emphasize that in the absence of significant changes in legislation, competences and financial incentives that promote research and development investments and innovations in industry, technologies, and services, the regions will fail to attract capital to support R\&D and innovation potential. In this regard, they will also fail in shaping a new structure of the economy based on long-term competitiveness.

In this paper, we analyze the relationship between the global competitiveness development quantified by the Global Competitiveness Index (GCI) and innovation performance measured on the basis of $\mathrm{R} \& \mathrm{D}$ expenditure per capita in the member states of the European Union that form the group of Central and Eastern European countries (CEE EU (11)).

The paper is organized as follows. Firstly, we review the empirical literature related to the issue concerning competitiveness on the global scale and innovation performance as a closely interconnected economic category. In the next chapter, we briefly introduce methodology and data. The empirical part of the study is focused on revealing potential relations between the international competitiveness development of the CEE EU (11) countries and their innovation capacity in terms of an analysis of gross domestic expenditure on R\&D per capita within the selected sectors of performance.

\section{THEORETICAL BACKGROUND}

Competitiveness is undoubtedly one of the most important concepts of economic science. Competition in the world markets is increasing, which encourages both businesses and national economies to be as competitive as possible. In this regard, Kravcakova-Vozarova et al. (2015) emphasize that a market economy is a competitive economy, and thus competition is undoubtedly a crucial part of economic activity. The World Economic Forum (WEF) defines competitiveness as the set of institutions, policies, and factors that determine the level of productivity of the country. The productivity of the country means a country's ability to maintain a high level of income, but it is also one of the main factors influencing the return on investment that reflects the growth potential of the specific economy (Schwab et al., 2017). According to Heckova et al. (2016), competitiveness means the ability of the economy to export goods and services to a sufficient extent and to reach an external economic balance, while ensuring a continuous increase of income per capita, a sufficient level of utilization of national factors and the achievement of other social and environmental goals. Early concepts of measuring competitiveness at the international level began to emerge in the 1980s. However, as reported by Ochotnicky et al. (2011), competitiveness reports published yearly by the WEF and the Institute for Management Development (IMD) have become the most accepted by governments, so they are now considered the most authoritative. These organizations assess and present internationally comparable results called a "competitiveness ranking," which represents a way of multi-criteria evaluation through various international aggregated indexes. 
Nowadays, the global competitiveness of countries is the subject of many empirical studies. Most authors focus on identifying factors that affect the overall score of international competitiveness indexes, whether in a positive or negative way, and formulate recommendations to improve the current state of the countries surveyed. For example, Tokarova (2015) analyzed theoretical views on the issues of national economies' competitiveness based on the indexes GCI, WCI and another one - SCI (Sustainability - Adjusted Global Competitiveness Index). Balcarova (2016) studied whether the differences in competitiveness among individual EU economies are, during the analyzed period, decreasing or not. Based on the data provided by the WEF and IMD, Loo (2015) focused on the competitiveness analysis of the BRIC nations over the previous 15 years. He identified the key challenges faced by each nation and proposed three factors that may have influenced the results: democracy, colonialism, and religion. An analysis of selected factors within certain pillars was also performed by Mikusova Merickova et al. (2017). Karnitis \& Karnitis (2016) focused on the determination of functional regularities and drivers of growth of EU economies as well as the development of a growth model, which can be used for sustainable planning and prediction. The analysis of several regularly published analytical indexes (Doing Business Index, Global Competitiveness Index, Global Innovation Index, and European Innovation Index) suggests a thesis on innovation as the basic driving force of EU economies.

In recent years, the role of innovation as a tool for increasing the global competitiveness has been intensively discussed in the literature. A key factor of the states' increasing competitiveness is assumed to be the innovation performance of enterprises, which is projected through innovative business processes into the innovation performance of the economy as a whole (Ivanová \& Čepel, 2018). In this context Dobeš et al. (2017) accent the role of governmental support in business. On the other side Tvaronavičiené \& Razminiené (2016) emphasize the role of clusters in competitive regional development.

As reported by Tiruneh \& Hekelova (2016), the economies with an advanced level of higher education, training and a higher level of innovation activities tend to reach a higher level of the GCI indicator compared to countries with lower levels of education and innovation performance. Identification of the usage of information and communication technology (ICT) on the international competitiveness of European countries was the subject of Zoroja's (2015) study. The findings revealed that ICT has the highest impact on the GCI indicator and especially on Efficiency enhancers' sub-index. Speaking about increasing the economic performance of enterprises under the conditions of Slovakia as the main driver of competitive advantage, the authors Rajnoha et al. (2016) recommend employing a system of strategic performance management of the firm supported by a knowledge-based Business Intelligence Information System (Rajnoha et al., 2016; Rajnoha \& Lorincova, 2015). In this context Vojtovič (2016) investigates the impact of the structural funds on competitiveness of SMEs. Dobrovic et al. (2016) worked on assumption that improvement of effectiveness of the system of an optimal tax collection is necessary for sustainable development of Slovak socio-economic system, which can lead to an increase in efficiency and higher competitiveness of our state among EU countries.

One of the most significant factors influencing the realization and development of innovation activities is undoubtedly the amount of public investment released to develop country's innovative potential. Szarowska (2017) quantified the impact of public research and development 
(R\&D) expenditure on economic growth of 20 selected EU member states in the period of 1995 - 2013. The author concluded that the effect of government R\&D is the main driver for economic growth with a stronger effect than traditional growth variables (investment and human capital approximated by HRST). Szczygielski, et al. (2017) also studied the impact of government grants for innovation activities in countries with a similar level of economic development, namely Turkey and Poland. The results confirmed a positive effect of government grants on development in innovation performance of companies in both countries. Czarnitzki \& LopezBento (2013) emphasize the importance and positive impact of government support by analyzing the effects of a specific government-sponsored commercial R\&D program from various angles. The authors of Simionescu et al. (2017) also studied determinants of the economic growth and competitiveness in the V4 countries and Romania. The main results indicated that the FDI promoted economic growth and competitiveness in all countries, except the Slovak Republic. Only in the Czech Republic, the expenditure on education generated economic growth, while the expenditure on R\&D had positive effects in Romania, Hungary, and the Czech Republic. Svagzdiene \& Kuklyte (2016), Wiedenhofer et al. (2017), Balog (2016) identified as the most significant factors influencing the innovation performance of countries (except for R\&D expenditure) also the number of researchers, number of patents issued, connection of labor market and vocational training system, internationalization of $\mathrm{R} \& \mathrm{D}$ activities or the degree of appropriate cluster policy implementation.

\section{RESEARCH OBJECTIVE AND METHODOLOGY}

The main aim of this paper is to reveal the relations between the R\&D expenditure and the global competitiveness development in the member states of European Union forming the group of Central and Eastern European countries (CEE EU (11)). The aggregation of the CEE EU (11) countries include the following states: Bulgaria (BG), Croatia (HR), the Czech Republic (CZ), Estonia (EE), Hungary (HU), Latvia (LV), Lithuania (LT), Poland (PL), Romania (RO), Slovakia (SK) and Slovenia (SI).

For this paper, we focused on the following research tasks:

Is there a statistically significant relationship between the R\&D expenditure (per capita) and the CEE EU (11) countries' global competitiveness development? Is there a statistically significant relation between alternatives of the GERD variables (GERD_T, GERD_B, GERD_G, and GERD_E) and GCI subindexes within the CEE EU (11) member states?

Secondary data concerning the gross domestic expenditure on R\&D (GERD) by sectors of performance were retrieved from the Eurostat (2018) database. Due to the incomplete availability of data within the selected group of countries we focused on the period of $2007-2016$. The impacts and consequences of the R\&D expenditure were analyzed in terms of GERD per capita on average for All sectors of performance, Business enterprise sector, Government sector and Higher education sector (a brief description of variables is shown in Tab. 1). The private nonprofit sector did not provide all the data necessary for a correct and complete comparison across the CEE EU (11) countries over the analyzed period, so we did not take it into account for the purposes of this research. 
Tab. 1 - List of variables examined in the analysis. Source: authors' processing

\begin{tabular}{|c|c|c|}
\hline Variable & Description & Source \\
\hline $\begin{array}{l}\text { GERD per capita } \\
\text { - All sectors of } \\
\text { performance } \\
\text { (GERD_T) }\end{array}$ & $\begin{array}{l}\text { Intramural R\&D expenditure (GERD) by all perform- } \\
\text { ance sectors - the CEE EU (11) countries ( } € \text { per inhabit- } \\
\text { ant on average) }\end{array}$ & \multirow{4}{*}{$\begin{array}{l}\text { Eurostat } \\
\text { database }\end{array}$} \\
\hline $\begin{array}{l}\text { GERD per } \\
\text { capita - Business } \\
\text { enterprise sector } \\
\text { (GERD_B) }\end{array}$ & $\begin{array}{l}\text { Intramural R\&D expenditure (GERD) in the Business } \\
\text { enterprise sector - the CEE EU (11) countries ( } € \text { per } \\
\text { inhabitant on average) }\end{array}$ & \\
\hline $\begin{array}{l}\text { GERD per capita } \\
\text { - Government } \\
\text { sector (GERD_- } \\
\text { G) }\end{array}$ & $\begin{array}{l}\text { Intramural R\&D expenditure (GERD) in the Govern- } \\
\text { ment sector - the CEE EU countries (11) (€ per inhabit- } \\
\text { ant on average) }\end{array}$ & \\
\hline $\begin{array}{l}\text { GERD per } \\
\text { capita - Higher } \\
\text { education sector } \\
\text { (GERD_E) }\end{array}$ & $\begin{array}{l}\text { Intramural R\&D expenditure (GERD) in the Higher } \\
\text { education sector - the CEE EU countries (11) ( } € \text { per } \\
\text { inhabitant on average) }\end{array}$ & \\
\hline $\begin{array}{l}\text { Global Competi- } \\
\text { tiveness Index } \\
(\mathrm{GCI})\end{array}$ & $\begin{array}{l}\text { Competitiveness assessment by means of } 12 \text { pillars inte- } \\
\text { grated into } 3 \text { subindexes - Basic requirements, Efficiency } \\
\text { enhancers and Innovation and sophistication factors } \\
\text { (score ranging from } 0-7 \text { ) }\end{array}$ & $\begin{array}{l}\text { World Eco- } \\
\text { nomic Fo- } \\
\text { rum database }\end{array}$ \\
\hline
\end{tabular}

The global competitiveness evaluation of the CEE EU (11) countries was measured by means of the Global Competitiveness Index (GCI), which achieves high recognition and appreciation from the governments of countries being evaluated. The data was collected on the basis of annually published Global Competitiveness Reports and available dataset processed by the World Economic Forum (WEF) over the period of 2006 - 2017.

The Global Competitiveness Index (GCI) is composed of 12 general economic pillars (see Tab. 2), which play an important role in its quantification. Individual pillars are integrated into three groups on the basis of their content and orientation and they are called "sub-indexes" according to the theory of M. Porter - Basic Requirements, Efficiency Enhancers and Innovation and Sophistication Factors. The weights of the individual subindexes are different depending on the stage of development of economies, whereas the weights of individual indicators remain constant. For countries considered to be "in transition", the weights change smoothly as a country develops, reflecting the smooth transition from one stage of development to another. Computation of the GCI indicator is based on successive aggregations of scores from the individual indicator level (the most disaggregated level) all the way up to the overall score of the GCI indicator (Schwab et al., 2017). As reported by Parausic et al. (2014), the GCI indicator is constructed by combining "hard" statistical data and "soft" data. "Hard data" are gathered from publicly available sources (International Monetary Fund, World Bank, UNESCO, World Health Organization, etc.) and normalized by point evaluation from 1 (worst) to 7 (best) as to correspond with another 
important component of this index - "soft data". They are received on the basis of Executive Opinion Survey (EOS) performed in each partner country. Respondents express their degree of agreement or disagreement with the survey statements on a scale from 1 to 7, where 1 represents the worst possible situation and 7 the best possible situation.

Tab. 2 - The structure of Global Competitiveness Index. Source: Schwab et al. (2017)

\begin{tabular}{|c|c|c|}
\hline $\begin{array}{l}\text { Subindex - Basic Re- } \\
\text { quirements }\end{array}$ & Subindex Efficiency Enhancers & $\begin{array}{l}\text { Subindex - Innovation and } \\
\text { Sophistication Factors }\end{array}$ \\
\hline $\begin{array}{l}\text { 1st pillar: Institutions } \\
\text { 2nd pillar: Infrastruc- } \\
\text { ture } \\
\text { 3rd pillar: Macroeco- } \\
\text { nomic environment } \\
\text { 4th pillar: Health and } \\
\text { primary education }\end{array}$ & $\begin{array}{l}\text { 5th pillar: Higher education and } \\
\text { training } \\
\text { 6th pillar: Goods market efficiency } \\
\text { 7th pillar: Labor market efficiency } \\
\text { 8th pillar: Financial market develop- } \\
\text { ment } \\
\text { 9th pillar: Technological readiness } \\
\text { 10th pillar: Market size }\end{array}$ & $\begin{array}{l}\text { 11th pillar: Business so- } \\
\text { phistication } \\
\text { 12th pillar: Innovation }\end{array}$ \\
\hline
\end{tabular}

Secondary data from the above-mentioned sources (Eurostat and WEF) were incorporated into the database of input indicators for the CEE EU (11) countries during the period of 2007 - 2016. For the purposes of further research analysis, we applied a correlation matrix, which is one of the multidimensional statistical methods. The main purpose of the correlation analysis is to estimate the intensity of the correlation dependence assessing the strength of the interconnection among the pair of variables. To reveal the interrelations and to determine the strength of interdependencies among the selected indicators, the non-parametric test of independence between two variables Kendall tau was employed. To process the above data, the STATISTICA software (version 13) was used.

\section{RESULTS AND DISCUSSION}

The following part of research is devoted to describing the analysis results aimed at revealing relations between the R\&D expenditure height within the CEE EU (11) countries and their competitiveness ratings by means of the Global Competitiveness Index (GCI).

In this regard, the empirical part of the paper is focused mainly on a deeper analysis of two selected indicators. The first input indicator is represented by the level of average R\&D expenditure in the CEE EU (11) countries during the years 2007 - 2016. Moreover, the expenditure on R\&D are analysed in terms of GERD per capita broken down into All sectors of performance, Business enterprise sector, Government sector and Higher education sector. The second input indicator is the competitiveness assessment of the CEE EU (11) countries measured by the GCI indicator over the period of 2006 - 2017. The possible availability of secondary data caused the difference in the analyzed periods. Within the comparison of countries' competitiveness rating development by means of the GCI indicator, we focused on the position of Slovakia, the CEE 
EU (11) countries as well as the EU (28) countries. Furthermore, we analyzed the development of GCI average score within the individual CEE EU (11) member states. The overall score of the GCI indicator consists of 3 sub-indexes of which development (in the above-mentioned group of countries) was the subject of the following analysis.

\subsection{The development analysis of R\&D expenditure within the CEE EU (11)}

The next part of this study is dedicated to the development analysis of the R\&D expenditure per capita in the CEE EU (11) countries during the years 2007 - 2016. The average values of analyzed expenditure according to individual countries included in this aggregation are the subject of Figure 1.

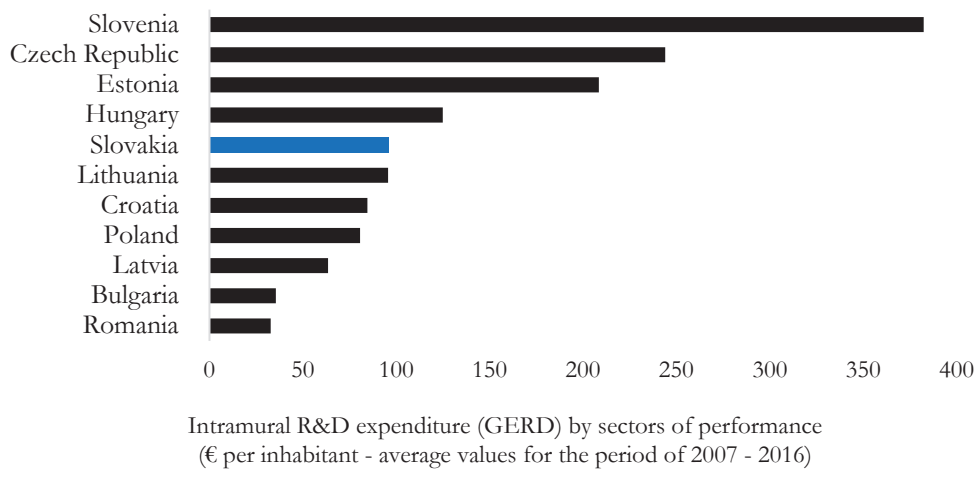

Fig. 1 - Intramural R\&D expenditure (GERD) per inhabitant $(€)$ by all sectors of performance. Source: authors' processing on the basis of Eurostat database

Over the analyzed period, the average level of R\&D expenditure in each country included in the CEE EU (11) group reached the value of $€ 131.60$ per capita. Compared to the EU (28) spending on R\&D ( $€ 524.50$ per capita on average), these financial resources cannot be considered sufficient. Surprisingly, Slovenia's total investment in R\&D activities per capita (€ 4,205.10) is the highest one over the analyzed years. By contrast, Romania was able to invest only $€ 32.80$ on average in research and development areas; therefore it occupies the last position. In this regard, Slovakia ranked 5 th on average $(€ 95.80$ per capita and $€ 1,053.70$ in total during the years 2007 - 2016) and only Slovenia, the Czech Republic, Estonia, and Hungary achieved better results. In summary, all countries included in the CEE EU (11) group invested $€ 15,928.50$ on average in $\mathrm{R} \& \mathrm{D}$ activities.

In the following part of the analysis, we dealt with the comparison of average $R \& D$ expenditure per capita among the individual CEE EU (11) member states in terms of selected performance sectors: Business enterprise sector, Government sector, and Higher education sector. 


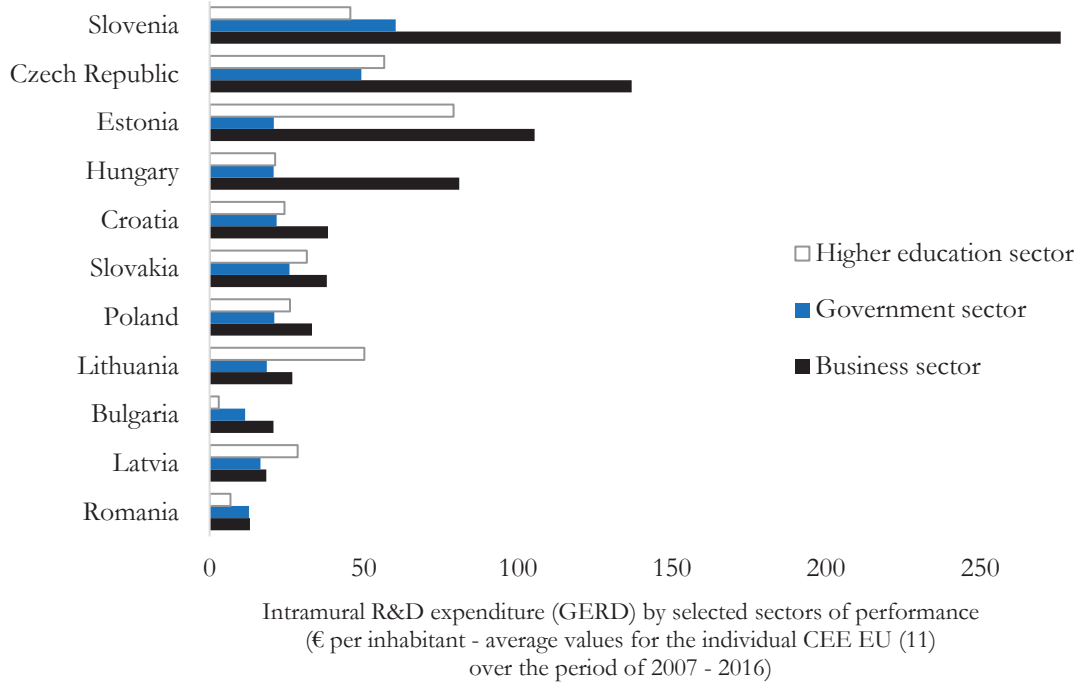

Fig. 2 - Intramural R\&D expenditure (GERD) per inbabitant $(€)$ by selected sectors of performance. Source: authors' processing on the basis of Eurostat database

When comparing the development of average $R \& D$ spending per capita by selected sectors, we found out that the CEE EU (11) countries' financial resources in research and development activities were invested mostly in the Business sector. From this point of view, Slovenia's spending in $R \& D$ reached undoubtedly the highest average level of $€ 276.10$ over the period monitored. On the other side, Romania's R\&D activities in the Business sector were supported only by $€$ 13.10 on average. Likewise in the case of the Government sector, Slovenia ranked 1st with average R\&D spending at the level of $€ 60.40$ and Bulgaria recorded the lowest investment in the above-mentioned areas (only $€ 11.50$ ). When evaluating the $R \& D$ expenditure within the last sector of performance (Higher education sector), the average value for all CEE EU (11) countries moved to the level of $€ 33.95$, whereas a dominant position was occupied by Estonia ( $€ 79.10)$. On the contrary, Bulgaria reached the worst results as it invested only $€ 3.00$ per capita in research and development activities in this sector. In summary, all CEE EU (11) member states invested $€ 788.20$ on average in the Business sector, only $€ 279.40$ in the Government sector and $€ 373.20$ in the Higher education sector.

\subsection{The competitiveness development analysis of CEE EU (11) member states}

The following part of global competitiveness analysis was aimed at the development of average GCI score in terms of the position of Slovakia, the CEE EU (11) member states and the EU (28) countries over the years $2006-2017$ (see Fig. 3). 


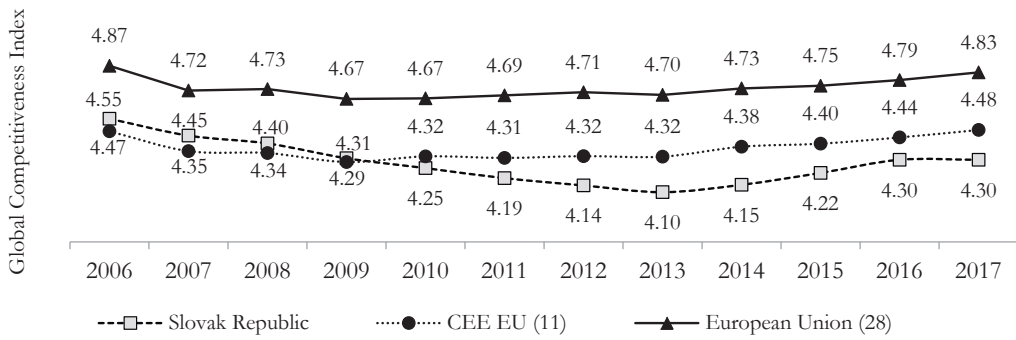

Fig. 3 - The development of average GCI score over the period of 2006-2017. Source: Authors' processing on the basis of WEF annual reports and dataset

Over the analyzed period of 2006 - 2017, the development trend of average GCI scores within the countries of CEE EU (11) group was almost identical to the average level of EU (28)'s GCI scores. In the case of EU (28) countries, the average scores ranged from a minimum value of 4.67 recorded in 2009 and 2010, up to the maximum value of 4.87 reached in 2006. However, it is worthy to note that the development of average GCI scores have recorded a favorable trend over the last four years and the EU (28) countries are constantly trying to get closer to the maximum value achieved in 2006. Within the CEE EU (11) member states, the highest GCI value on average was identified in 2017 (4.48). Compared to 2006, there was a slight improvement by only 0.01 points, but taking into account the lowest value achieved in 2009, the GCI indicator finally improved by $4.43 \%$. During the years 2006 - 2009, Slovakia's GCI score was above the average level achieved by the CEE EU (11) member states, but after 2009, it recorded an ongoing decreasing trend; therefore, Slovakia is currently still lagging behind the average score of the CEE EU (11) countries. The highest overall score of Slovakia's GCI indicator was achieved in 2006 (4.55). Contrary to this, the lowest score was recorded in 2013 (4.10), but it increased by 2017 to the level of 4.30. Despite the unfavourable development of Slovakia's GCI score in comparison with the CEE EU (11) member states, we consider recent development to be positive as the average level of GCI score is getting closer not only to values of the CEE EU (11) countries but also to the maximum values reached by Slovakia in 2006 .

Further analysis provides an insight into the development of average GCI values within the individual CEE EU (11) member states (see Fig. 4).

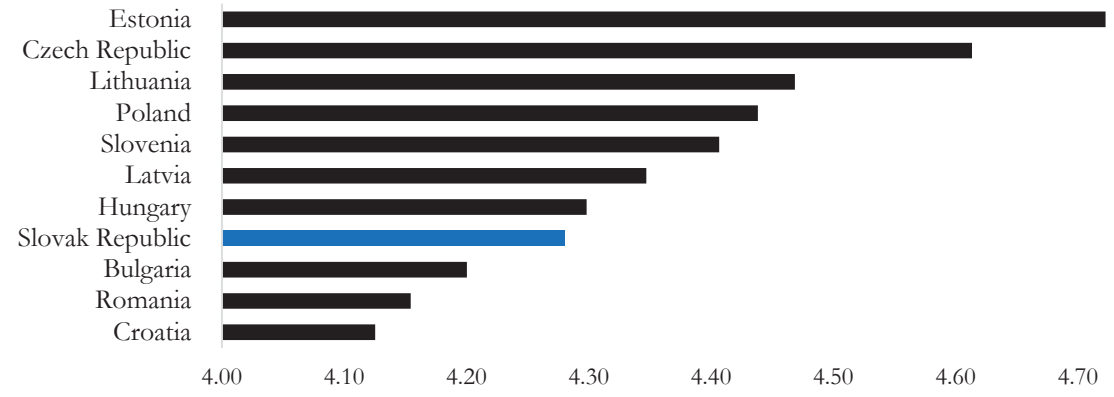

Fig. 4 -The average level of GCI score within the CEE EU (11) over the years of 2006 - 2017. Source: Authors' processing on the basis of WEF annual reports and dataset. 
Over the analyzed period of 2006 - 2017, the GCI score of EU (28) countries reached the level of 4.74 on average. Based on a more detailed analysis of the average GCI scores within the above mentioned group of countries, we found out that none of the countries attained a higher score than the EU (28) average. This fact can be also confirmed by the average GCI score in the case of the CEE EU (11) member states, which was at the level of 4.37. When comparing the individual CEE EU (11) countries, we can state that only 5 countries (Estonia, the Czech Republic, Lithuania, Poland and Slovenia) were able to achieve higher GCI scores on average than all countries together within this aggregation. On the contrary, the Slovak Republic was included in the group of six countries lagging behind the average GCI scores of the CEE EU (11) member states. In this regard, only Bulgaria, Romania and Croatia achieved worse results than Slovakia. Within the competitiveness rankings of individual countries of the CEE EU (11) group, Estonia ranked 1st on average (4.72) and lagged behind the level of GCI EU (28) score by an index of 0.9964 . The last position was reached by Croatia with the GCI score at the average level of 4.13.

Based on the comparative analysis of the GCI indicator development across the CEE EU (11) member states, we can conclude that the lowest value was achieved by Bulgaria (3.93) over the whole period analyzed. The highest score of the GCI indicator was recorded in the case of Estonia (5.12) in 2006. Besides that, this country reached the best overall score every year. Only one exception was recorded in 2009 when the Czech Republic became the leader of the CEE EU (11) group. Interesting results were also found out within the development analysis of GCI indicator in the case of the CEE EU (11) member states. In this regard, the worst average value was reached in 2009. This year was identified as the least favorable also in the case of Slovakia; however, the development trend of the CEE EU (11) countries has been constantly improving in the following years (with one negligible exception in 2011). We consider this development to be positive as it indicates the desired progress and favorable opportunities for the future.

The development and comparison of the CEE EU (11)'s positions were also done on the basis of individual GCI subindexes - 1_Subindex Basic Requirements, 2_Subindex Efficiency Enhancers and 3_Subindex Innovation and Sophistication Factors (see Fig. 5).

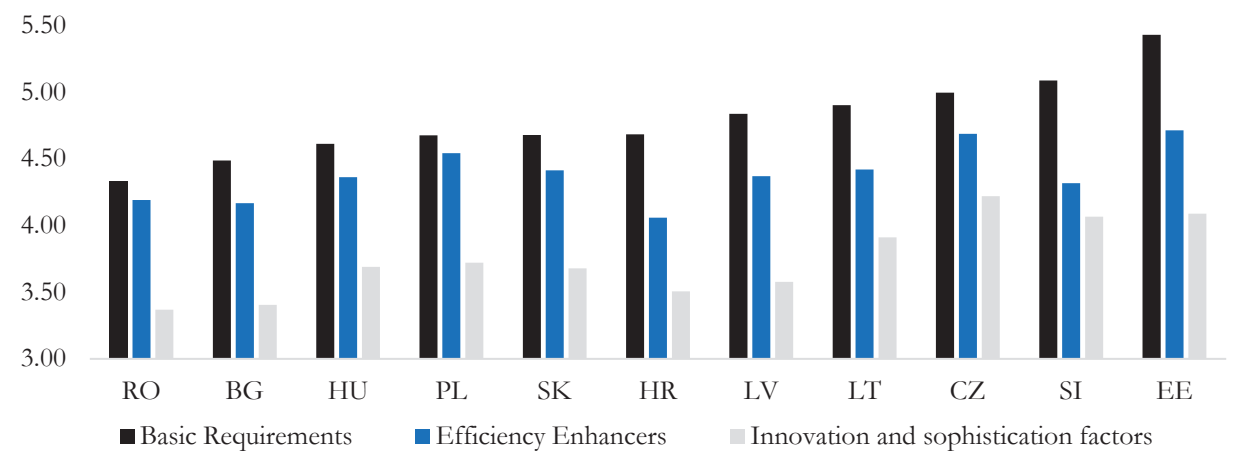

Fig. 5 - The average level of GCI subindexes within the CEE EU (11) over the years 2006 - 2017. Source: authors' processing on the basis of WEF annual reports and dataset 
Based on the achieved average values of the individual GCI subindexes over the years 2006 -2017, we can conclude that the highest average value from all three subindexes (and also within all CEE EU (11) countries) was reached by 1st subindex (Basic Requirements), vice versa, the lowest score was recorded in the case of 3rd subindex (Innovation and Sophistication Factors). When evaluating the 1st GCI subindex, Estonia achieved the highest average score (5.43), while Romania reached the lowest one (4.33). The results of average values for 2nd GCI subindex within the CEE EU (11) member states have confirmed the leadership of Estonia (4.71), whereas the last position was reached by Croatia (4.06). Over the years 2006 - 2017, the above-mentioned GCI subindex for all CEE EU (11) countries attained an average score at the level of 4.39. The competitiveness ranking of these countries in terms of 3rd GCI subindex has changed and the leading position with the highest score (4.22) was obtained by the Czech Republic. On the contrary, Romania occupied the last place and according to its positions within all GCI subindexes (11th, 9th, 11th), it is considered to be the weakest country among the CEE EU (11) member states. Interestingly, according to an average score of all GCI subindexes, Bulgaria ranked 10th and Latvia 4th. Over the analyzed years, the highest average scores of the GCI subindexes and also the top rankings were reached by Estonia (1st, 1st, 2nd) among all countries surveyed.

\subsection{The results of the correlation analysis}

The main objective of this study is to reveal the relations between the R\&D expenditure and global competitiveness development in the CEE EU (11) countries. To assess the interrelations between the analyzed variables, a correlation matrix as one of the multidimensional statistical methods was used. The main purpose of the correlation analysis is to estimate the intensity of the correlation dependence assessing the strength of interconnection among the pairs of vari-

ables. To reveal the interrelations and to determine the strength of the interdependencies among the selected indicators, the non-parametric test of independence between two variables Kendall tau in the STATISTICA software was employed.

To identify the relationship between R\&D expenditure and CEE EU (11) countries' competitiveness measured by the Global Competitiveness Index for the period of 2007 - 2016, we conducted the correlation analysis by using the following selected variables:

- alternatives to the GERD variables (GERD_T, GERD_B, GERD_G, GERD_E) for the CEE EU (11) member states,

- alternatives of the GCI variable (the GCI indicator and three main GCI subindexes) for the CEE EU (11) member states.

The results of the non-parametric test Kendall tau are the subject of Table 3. The mutual relation intensity between two variables is analyzed at the significance levels of $\alpha=5 \%$ and $\alpha=1 \%$. The coefficients of the Kendall tau test are ranging within the interval $<-1,1>$. The interpretation of Kendall tau correlation coefficient was realized on the basis of Cohen (1998) scale. The correlation coefficient value higher than 0.5 is referred to as a large correlation, the value ranging from 0.3 to 0.5 represents a medium correlation, the value ranging from 0.1 to 0.3 is referred to as a small correlation and if the correlation coefficient reaches the value lower than 0.1 , the correlation between variables is trivial. 
The main aim of this correlation analysis was to identify the intensity of relations between the R\&D expenditure and the global competitiveness development within the CEE EU (11) member states. Firstly, we have identified the correlation dependence between the total R\&D expenditure for all performance sectors and the overall GCI score. The next part was focused on revealing possible interconnections between the individual GCI subindexes (Basic Requirements, Efficiency Enhancers, Innovation and Sophistication Factors) and R\&D expenditure by selected sectors of performance (GERD_T, GERD_B, GERD_G, GERD_E). The results of the correlation analysis (by using the non-parametric Kendall tau test) identified among the R\&D expenditure, the overall GCI scores, and individual GCI subindexes are presented in the following Tab. 3.

Tab. 3 - The correlation among GERD, GCI scores, and GCI subindexes within the CEE EU (11). Source: authors' processing in the STATISTICA software

\begin{tabular}{|l|l|l|l|l|}
\hline Variable / Kendall tau & GCI & $\begin{array}{l}\text { 1st Subindex } \\
\text { of GCI }\end{array}$ & $\begin{array}{l}\text { 2nd Subindex } \\
\text { of GCI }\end{array}$ & $\begin{array}{l}\text { 3rd Subindex } \\
\text { of GCI }\end{array}$ \\
\hline GERD_T & $0.3808^{* *}$ & $0.5621^{* *}$ & $0.3025^{* *}$ & $0.5541^{* *}$ \\
\hline GERD_B & $0.3327^{* *}$ & $0.4874^{* *}$ & $0.2536^{* *}$ & $0.4718^{* *}$ \\
\hline GERD_G & $0.2320^{* *}$ & $0.3934^{* *}$ & $0.2323^{* *}$ & $0.4349^{* *}$ \\
\hline GERD_E & $0.4717^{* *}$ & $0.6376^{* *}$ & $0.3771^{* *}$ & $0.5813^{* *}$ \\
\hline
\end{tabular}

Note: ** indicates significance level of $0.01, *$ indicates significance level of 0.05

Based on the correlation coefficient values among the R\&D expenditure (including individual sectors of performance) and the GCI indicator, a medium dependence within all variables was confirmed. The small dependence intensity at the level of 0.2320 was revealed only in the case of the Government sector. Interestingly, we identified the most significant statistical dependence between the GCI indicator and the R\&D expenditure in the Higher education sector (GERD_ E) at the level of 0.4717. Paradoxically, the previous analysis has demonstrated that the above mentioned sector was the least funded within the all CEE EU (11) member states. All correlation coefficients were confirmed at the significance level of 0.01 , so we can conclude that there is a medium correlation between the analyzed variables (GERD and GCI).

In the second part of the correlation analysis, a statistically significant dependence of $\mathrm{R} \& \mathrm{D}$ expenditure in relation to all GCI subindexes with medium to large intensity was proved. According to the Cohen scale, we detected the most significance dependence in the case of the 1st GCI subindex (0.6376) with the R\&D expenditure in the higher education sector (GERD_E). A large dependence was also confirmed by the total R\&D expenditure (GERD_T) and a medium dependence within the other R\&D expenditure sectors (GERD_B, GERD_G). The correlation dependence between the R\&D expenditure and the 2nd GCI subindex (Efficiency Enhancers) was referred to as medium and small for all expenditure alternatives, whereas the average value of correlation dependence reached the level of 0.2914. As in the case of the 1st GCI subindex (Basic Requirement), the most significant dependence (0.3771) was identified also with the R\&D expenditure in the higher education sector (GERD_E). Within the correlation analysis between the 3rd GCI subindex (Innovation and Sophistication Factors) and individual R\&D expenditure, 
a statistically significant dependence was proved among all the analyzed variables. In this regard, the largest dependence intensity (0.5813) was again confirmed in the case of the R\&D expenditure in the higher education sector (GERD_E). Moreover, we detected a large statistical dependence between this subindex and the total R\&D expenditure. The remaining two R\&D sectors (GERD_ B and GERD_G) correlated with the 3rd GCI subindex within the scale of a medium intensity and a correlation coefficient at the level of 0.4534 on average. All correlation coefficients were confirmed at the significance level of 0.01 , so there is a large correlation intensity between the four variables analyzed (GERD_T, GERD_E, and 1_Subindex of GCI, 3_Subindex of GCI), while in other cases, a medium dependence between the indicators was confirmed.

\section{CONCLUSION}

Many international organizations, international research institutes or foundations compile annual multi-criteria evaluations of competitiveness, leading to the creation of worldwide rankings where countries defend not only their overall position but also the position in the selected areas. Each country follows its range of important economic aspects and features and compares them with other states at the global level (Sofrankova et al. 2017).

The main aim of this paper was to determine the relationship between R\&D expenditure and the global competitiveness development in the Central and Eastern European member states of the European Union (CEE EU (11)).

Over the period of 2007 - 2016, the CEE EU (11) countries' total R\&D expenditure per capita reached the average level of $€ 15,925.47$, whereas the $R \& D$ expenditure in the business enterprise sector represented $49.50 \%$ of the total spending on $R \& D$ activities ( $€ 7,822.40$ per capita). The $\mathrm{R} \& \mathrm{D}$ expenditure in the higher education sector accounted for $23.40 \%$ of total expenditure (€ 3,731.80 per capita). Approximately $€ 2,793.50$ per capita was invested in research activities within the government sector, and the remaining $9.60 \%$ of total R\&D expenditure in the private non - profit sector. Slovenia's total investment in R\&D activities per capita $(€ 4,205.10)$ is the highest one over the analyzed years. By contrast, Romania was able to invest only $€ 32.80$ on average in research and development areas; therefore it has occupied the last position. In this regard, Slovakia ranked 5th on average ( $€ 95.80$ per capita) during the years $2007-2016$.

Within the CEE EU (11) member states, the highest average GCI value was identified in 2017 (4.48) and the lowest one in 2009 (4.31). The highest average values of the GCI indicator were reached in the case of Estonia (4.72) and the lowest for Croatia (4.13). Slovakia was included in the group of six countries lagging behind the average GCI scores of CEE EU (11) member states and is ranked 8 th on average (4.38) over the whole period analyzed.

Within the CEE EU (11) countries' competitiveness analysis in terms of achieved average values of the individual GCI subindexes over the years 2006 - 2017, the highest average value from all three subindexes was reached by the 1st GCI subindex (Basic Requirements), and vice versa, the lowest score was recorded in the case of the 3rd GCI subindex (Innovation and Sophistication Factors). The highest average scores of all GCI subindexes were reached by Estonia (1st, 1st, 2nd place) and last places were occupied mostly by Romania (11th, 9th, 11th). The analysis also indicated the interesting ranking of 2 countries - Bulgaria placed 10th and Latvia 4th within all 
GCI subindexes. In this regard, Slovakia ranked 7th (within the 1st and 3rd GCI subindexes) and 5th (within the 2nd GCI subindex).

The correlation analysis results confirmed the existence of a statistically significant dependence between the GCI indicator and all variants of the R\&D expenditure within the CEE EU (11) member states over the period of 2007 - 2016. On the basis of the correlation analysis results, we can conclude that the most significant dependence was indicated between the R\&D expenditure in the higher education sector (GERD_E) in relation to the overall GCI indicator assessment including its three main subindexes. The highest correlation value within the performed analysis was confirmed between the R\&D expenditure in the higher education sector (GERD_E) and the 1st GCI subindex $(\tau=0.6376, \mathrm{p}<0.01)$, followed by relation to the the 3 rd GCI subindex $(\tau$ $=0.5813, \mathrm{p}<0.01)$ and the total GCI indicator $(\tau=0.4717, \mathrm{p}<0.01)$.

To conclude, we may state that the growth of $R \& D$ expenditure can significantly contribute to increasing the CEE EU (11) countries' competitiveness levels. All performed analyses confirmed that it is important to focus on increasing the $R \& D$ expenditure, especially in the higher education sector with stimulation of grant funding in cooperation with the government and business sector. It has a significant influence on improving the global competitiveness development of the CEE EU (11) countries in the case of the 1st and 3rd GCI subindexes. In the end, it will also be reflected in the overall competitiveness assessment of this group of countries.

\section{ACKNOWLEDGMENT}

This work was supported by the Slovak Research and Development Agency under the contract No. APVV15-0322 and by the project VEGA 1/0791/16 - "Modern approaches to improving enterprise performance and competitiveness using the innovative model - Enterprise Performance Model to streamline Management Decision-Making Processes."

\section{References}

1. Balcarova, P. (2016). Is Competitiveness in the European Union Converging? Acta Universitatis Agriculturae et Silviculturae Mendelianae Brunensis, 64 (6), 1835-1842. http://dx.doi.org/10.11118/ actaun201664061835

2. Balog, M. (2016). Development Factors of Cluster Organizations in the Slovak Republic. Journal of Economics, 64 (2), 148-168.

3. Cohen, J. (1998). Statistical power analysisfor the behavioral sciences. 2nd ed. Hillsdale, NJ: Lawrance Earlbaum Associates.

4. Czarnitzki, D., \& Lopez-Bento, C. (2013). Value for Money? New Microeconometric Evidence on Public R\&D Grants in Flanders. Research Policy, 42 (1), 76-89. http://dx.doi. org/10.1016/j.respol.2012.04.008

5. Dell Inc. (2016). Dell Statistica (data analysis software system), version 13. software.dell.com.

6. Dobeš, K., Kot, S., Kramoliš, J., \& Sopková, G. (2017). The Perception of Governmental Support in The Context of Competitiveness of SMEs in the Czech Republic. Journal of Competitiveness, 9 (3), 34-50. DOI: 10.7441/joc.2017.03.03.

7. Dobrovic, J., Koraus, A. \& Dancisinova, L. (2016). Sustainable Economic Development of Slovakia: Factors Determining Optimal Tax Collection. Journal of Security and Sustainability Issues, 5 (4), 533-544. https://doi.org/10.9770/jssi.2016.5.4(8) 
8. Eurostat (2018). Retrieved January 25, 2018, from http://ec.europa.eu/eurostat/data/ database

9. Habanik, J., Kordos, M. \& Hostak, P. (2016). Competitiveness of Slovak Economy and Regional Development Policies. Journal of International Studies, 9 (1), 144-155. https://doi. org/10.14254/2071-8330.2016/9-1/10

10. Heckova, J., Chapcakova, A. \& Markova, S. (2016). Analysis of the Current State of Qualitative Competitiveness of EU Economies. eXclusive Journal Economy \& Society \& Environment, 4 (3), $46-53$.

11. Hunady, J., Pisar, P., Musa, H., \& Musova, Z. (2017). Innovation Support and Economic Development at the Regional Level: Panel Data Evidence from Visegrad Countries. Journal of International Studies, 10 (3), 147-160. https://doi.org/10.14254/2071-8330.2017/10-3/11

12. Ivanová,E.\&Čepel,M. (2018). The Impact of Innovation Performance on the Competitiveness of the Visegrad 4 Conutries. Journal of Competitiveness, 10 (1), 54-72. https://doi.org/10.7441/ joc. 2018.01 .04

13. Karnitis, G. \& Karnitis, E. (2017). Sustainable Growth of EU Economies and Baltic Context: Characteristics and Modelling. Journal of International Studies, 10 (1), 209-224. https://doi. org/10.14254/2071-8330.2017/10-1/15

14. Kravcakova-Vozarova, I., Kotulic, R. \& Sira, E. (2015). V4 countries' agricultural sector evaluation in terms of competitive advantage. Economic Annals-XXI, 5-6, 60-63.

15. Loo, M., K. (2015). The Global Competitiveness of BRIC Nations: Performance, Issues and Implications for Policy. Review of Integrative Business and Economics Research, 4 (4), $22-62$.

16. Mikusova Merickova, B., Nemec, J., Murray Svidronova, M. \& Pischko, V. (2017). Analysis of the Relationship between the Size and Structure of Public Expenditure and Socio-Economic Development. Journal of Economics, 64 (4), 320-333.

17. Ochotnicky, P., Lajzova, B. \& Kiselakova, D. (2011). Price Competitiveness and Taxation of Energy Inputs. Journal of Economics, 59 (8), 786-801.

18. Parausic, V. et al. (2014). Correlation between the State of Cluster Development and National Competitiveness in the Global Competitiveness Report of the World Economic Forum 20122013. Economic research, 27 (1), 662-672. https://doi.org/10.1080/1331677X.2014.974917

19. Rajnoha, R., Stefko, R., Merkova, M. \& Dobrovic, J. (2016). Business Intelligence as a Key Information and Knowledge Tool for Strategic Business Performance Management. E \& $M$ Ekonomie a Management, 19 (1), 183-203. https://doi.org/10.15240/tul/001/2016-1-013

20. Rajnoha, R. \& Lorincová, S. (2015). Strategic Management of Business Performance Based on Innovations and Information Support in Specific Conditions of Slovakia. Journal of Competitiveness, 7 (1), 3-21. https://doi.org/10.7441/joc.2015.01.01.

21. Schwab, K. \& Sala-i-Martin, X. et al. (2017). Key Findings of the Global Competitiveness Index. The Global Competitiveness Report 2016-2017.

22. Simionescu, M., Lazányi, K., Sopková, G., Dobeš, K., \& Balcerzak, A. P. (2017). Determinants of Economic Growth in V4 Countries and Romania. Journal of Competitiveness, 9 (1), 103-116. https://doi.org/10.7441/joc.2017.01.07 
23. Svagzdiene, B. \& Kuklyte, J. (2016). The Analysis of Factors which have Impact on Summary Innovation Index in Germany, Estonia, and Lithuania. Transformations in Business \& Economics, 15 (2), 784-799.

24. Szarowska, I. (2017). Does Public R\&D Expenditure Matter for Economic Growth? GMM Approach. Journal of International Studies, 10 (2), 90-103. https://doi.org/10.14254/2071$8330.2017 / 10-2 / 6$

25. Szczygielski, K., Grabowski, W., Pamukcu, M. T. \& Tandogan, V. S. (2017). Does Government Support for Private Innovation Mater? Firm-level Evidence from Two Catching-up Countries. Research Policy, 46 (1), 219-237.

26. Sofrankova, B., Kiselakova, D. \& Cabinova, V. (2017). Innovation as a source of country's global competitiveness growth. Innovative Economic Symposium 2017 (IES2017): Strategic Partnership in International Trade, October 19, 2017, České Budejovice, Czech Republic. https:// doi.org/0.1051/shsconf/20173901026

27. Tiruneh, M. W. \& Hekelova, E. (2016). Is the Global Competitiveness Index informative? CBU International Conference on Innovations in Science and Education (CBUIC). 132-141. https://doi. org/10.12955/cbup.v4.754

28. Tokarova, M. (2015). Selected Problems of Competitiveness Measuring in Conditions of Globalization. The 15th International Scientific Conference "Globalization and its Socio-Economic Consequences“, Ed. by Kliestik, T. October 7-8, 2015, Rajecke Teplice, Slovak Republic, 800809.

29. Tvaronavičiené, M. \& Razminiené, K. (2017). Towards Competitive Regional Development Trough Clusters. Journal of Competitiveness, 9 (4), 133-147. https://doi.org/10.7441/ joc.2017.04.09

30. Vojtovič, S. (2016). The Impact of The Structural Funds on Competitiveness of Small and Medium-Sized Enterprises. Journal of Competitiveness, 8 (4), 30-45. https://doi.org/10.7441/ joc.2016.04.02

31. WEF (2018). Retrieved January 20, 2018. https://www.weforum.org/reports.

32. Wiedenhofer, R., Friedl, C., Billy, L. \& Olejarova, D. (2017). Application of IC-models in a Combined Public Private Sector Setting for Regional Innovation in Slovakia. Journal of Intelectual Capital, 18 (3), 588-606. https://doi.org/10.1108/JIC-11-2016-0110

33. Zoroja, J. (2015). Fostering competitiveness in European countries with ICT: GCI Agenda. International Journal of Engineering Business Management, 7 (18), 1-8. https://doi. org $/ 10.5772 / 60122$

\section{Contact information}

doc. Ing. Dana Kiselakova, PhD.

University of Presov in Presov

Faculty of Management, Department of Finance

Slovakia

E-mail:dana.kiselakova@unipo.sk

ORCID: 0000-0001-5662-5809 
Ing. Beata Sofrankova, PhD.

University of Presov in Presov

Faculty of Management, Department of Finance

E-mail: beata.sofrankova@unipo.sk

Slovakia

ORCID: 000-0001-9766-0467

Mgr. Veronika Cabinova

University of Presov in Presov

Faculty of Management, Department of Finance

E-mail:veronika.cabinova@smail.unipo.sk.

Slovakia

ORCID: 000-0003-4367-3590

Mgr. Erika Onuferova

University of Presov in Presov

Faculty of Management, Department of Finance

E-mail:erika.onuferova@smail.unipo.sk.

Slovakia

ORCID: 0000-0001-8529-8843

Ing. Janka Soltesova

University of Presov in Presov

Faculty of Management, Department of Finance

E-mail:janka.soltes@gmail.com

Slovakia 